\title{
Isolation of Bile Salt Hydrolase and Uricase Producing Lactobacillus brevis SF121 from Pak Sian Dong (Fermented Spider Plant) for using as Probiotics
}

\author{
Atipat Yasiri' ${ }^{1 *}$ (D) and Supawadee Seubsasana² \\ ${ }^{1}$ Chulabhorn International College of Medicine, Thammasat University, Pathum Thani 12120 , Thailand. \\ ${ }^{2}$ Faculty of Pharmacy, Thammasat University, Pathum Thani 12120, Thailand.
}

\begin{abstract}
The interesting application of bile salt hydrolase enzyme is reduction of cholesterol in serum and amelioration lipid profile. While uricase enzyme can be applied to convert insoluble uric acid to be soluble form and excrete from the body. Probiotics are living organisms with generally know that they can provide beneficial effects to their host. Several reports show that probiotic bacteria with bile salt hydrolase and uricase can improve hypercholesterolemia and hyperuricemia patient. The novel isolate of Lactobacillus from Pak Sian Dong in this study is identified as L. brevis SF121 and probably use as probiotic bacteria in the future. However, this isolate still need further experiments to investigate and improve properties of probiotics. Moreover, this finding suggests that Pak Sian Dong or fermented spider plant can be designated as a good source for probiotic screening and also defines as healthpromoting diet.
\end{abstract}

Keywords: Lactobacillus, bile salt hydrolase, uricase, spider plant

*Correspondence: payjamaz@yahoo.com; +66-2-5644440-9

(Received: June 30, 2020; accepted: September 04, 2020)

Citation: Yasiri A, Seubsasana S. Isolation of Bile Salt Hydrolase and Uricase Producing Lactobacillus brevis SF121 from Pak Sian Dong (Fermented Spider Plant) for using as Probiotics. J Pure Appl Microbiol. 2020;14(3):1715-1722. doi: 10.22207/JPAM.14.3.10

(C) The Author(s) 2020. Open Access. This article is distributed under the terms of the Creative Commons Attribution 4.0 International License which permits unrestricted use, sharing, distribution, and reproduction in any medium, provided you give appropriate credit to the original author(s) and the source, provide a link to the Creative Commons license, and indicate if changes were made. 


\section{INTRODUCTION}

Lactobacillus is gram positive bacteria in order Lactobacillales and commonly are defined as lactic acid producing bacteria based on their major by-product. This bacteria normally can be found in the environment, dairy product, animal gastrointestinal tract and fermented food.

Several studies have been reported that fermented food can be appropriated as the sources of lactic acid bacteria and also probiotics ${ }^{1-10}$. Probiotic bacteria with good properties are usually isolated from fermented vegetable, such as kimchi ${ }^{11}$ and sauerkraut ${ }^{12,13}$.

Pak Sian Dong is a kind of fermented vegetable in Thailand, which made from spider plant. Spider plants are affiliated with Cleomaceae family and designated the scientific name as Cleome gynandra L. These plants usually are observed worldwide, including Thailand. Fermentation can degrade toxic substance, called hydrocyanic which is defined as a neurotoxin, in spider plant then this kind of food will be safe to consume ${ }^{14}$.

Probiotics are assigned as living organism such as bacteria, mold and yeast, which provide advantages to their living host. The first screening criteria for probiotic bacteria are colonizing properties, which are able to attach the surface of the host and can survive in a gastrointestinal tract environment. The other criteria are beneficial properties that promote the health status of the host ${ }^{15-17}$.

Deconjugation of bile acid is occurred by catalytic enzyme calls bile salt hydrolase. Various bacteria have ability to produce this enzyme, especially lactic acid bacteria and Enterobacteria. The interesting application for bile salt hydrolase is cholesterol lowering. There are many reports that used bile salt hydrolase producing bacteria for decreasing of cholesterol level in blood of animal models and human volunteers ${ }^{18-20}$.

Gout is a disease which links to serum uric acid. Resulting of solubility of uric acid in blood is low, high level of this substance can cause precipitation of uric acid crystal leading to inflammation of joints. Therapeutic of this disease is probably aiming at; first, reduction of uric acid production by using allopurinol drug for xanthine oxidase activity inhibition; second, using probenecid to inhibit tubular reabsorption of uric acid and; third, using pegloticase for acting as uricase enzyme ${ }^{21,22}$. Uricase or urate oxidase enzyme has ability to transform insoluble uric acid to allantoin which is soluble substance and can be excreted by the kidney. Therefore, catalytic for uric acid activity, uricase is interested to be used for hyperuricemia and gout. Variety genus of bacteria have been screened and isolated with uricase activity, such as Bacillus ${ }^{23,24}$, Pseudomonas $^{25}$ and Lactobacillus ${ }^{26}$.

The objective of this study was the determination of bile salt hydrolase activity, uricase activity and colonizing properties in Lactobacillus brevis which was isolated from Pak Sian Dong in Pathum Thani, Thailand.

\section{MATERIALS AND METHODS}

\section{Strain isolation and cultivation conditions}

Lactobacillus brevis SF121 was isolated from Pak Sian Dong. Pak Sian Dong were purchased from local area in Pathum Thani province, a gram of each sample was mixed with $9 \mathrm{ml}$ of $\mathrm{NaCl}, 0.9 \%$ $(\mathrm{w} / \mathrm{v})$ or normal saline solution (NSS). The mixture was cultured on MRS agar which contained $\mathrm{CaCO}_{3}$ $0.5 \%(\mathrm{w} / \mathrm{v})$ and the plates were incubated for $48 \mathrm{~h}$ at $37^{\circ} \mathrm{C}$ incubator. Clear zone from $\mathrm{CaCO}_{3}$ degradation was observed around the colony and the colony was picked to determine for lactic acid bacteria characteristics. The characteristics were included gram reaction with positive results and catalase test with negative results. Blood hemolytic zone of the isolate was also observed after $37^{\circ} \mathrm{C}$ incubated at least $72 \mathrm{~h}$. All bacterial isolates were named which including $L$. brevis SF121 and stored at $-80^{\circ} \mathrm{C}$ in glycerol until used.

Bile salt hydrolase activity and uricase activity

For determination of bile salt hydrolase activity of the isolates, MRS medium with $0.5 \%(\mathrm{w} / \mathrm{v})$ of glycodeoxycholic acid (GCDA) (SigmaAldrich, USA) or taurodeoxycholic acid (TDCA) (Sigma-Aldrich, USA) were prepared as described by Yasiri et al. ${ }^{27}$. The isolates were streaked on GDCA- or TDCA-MRS agar plate and then placed at $37^{\circ} \mathrm{C}$ for $48-72 \mathrm{~h}$. After incubation, colony with halozone was observed and recorded for ability to produce bile salt hydrolase.

To determine uricase activity, plate assay with modification was performed ${ }^{23,25}$. The isolate 
was streaked on MRS agar containing $0.5 \%(\mathrm{w} / \mathrm{v})$ uric acid (Sigma-Aldrich, USA) and clear zone were observed after incubation for $48-72 \mathrm{~h}$ at $37^{\circ} \mathrm{C}$.

\section{Strain identification}

API50CHL (Biomerioux, France) was used to identify the strain. In addition, the 16s rRNA sequence analysis also was used to confirm species of the strain. The bacterial genomic DNA of the isolate was extracted with GF-1 bacterial DNA extraction kit (Vivantis, Malaysia) and amplification of 16s rRNA by $P C R$ was performed. The forward universal primer F8 (5'-AGAGTTTGATCCTGGCTCAG-3') and reverse universal primer R1492 (5'-GGTTACCTT GTTACGACTT-3') were used for amplification. After PCR amplification and agarose gel electrophoresis, Novel Juice (GeneDireX, USA) was mixed with the product and then observed the result on $0.8 \%$ (w/v) agarose (Invitrogen, USA). The PCR products were sequenced and the sequencing results were compared with a database (NCBI).

\section{Gastric fluid and bile salt tolerance}

To determine the tolerance of gastric fluid and bile salt, the procedure with slightly modified from Mota et al. was followed ${ }^{28}$. Synthetic gastric fluid was prepared as follows; weighed $\mathrm{NaCl}$ for 2 $\mathrm{g}$ and pepsin for $3.2 \mathrm{~g}$ and then mixed in $1000 \mathrm{ml}$ of water. Added concentrated hydrochloric acid to solution to make the $\mathrm{pH} 2.5$ and finally the solution was sterilized by filtration with $0.22 \mu \mathrm{m}$ pore size membrane. To determine gastric fluid tolerance, bacterial suspension was prepared by washing and adjusting the overnight culture of $L$. brevis SF121 with NSS to McFarland standard no. 0.5 . A hundred microliter of the $L$. brevis SF121 cell suspension was applied to $900 \mu \mathrm{l}$ of synthetic gastric fluid and incubated for $3 \mathrm{~h}$ at $37^{\circ} \mathrm{C}$. NSS was used instead of synthetic gastric fluid as a control group. The bacterial survival was evaluated and calculated on MRS agar by drop plate technique. For bile salt tolerance test, liquid MRS with $0.3 \%$ (w/v) of bile salt was prepared and inoculated with $1 \%$ inoculum of $L$. brevis SF121 overnight culture. The numbers of bacteria were determined with the plate count technique at $0 \mathrm{~h}$ and $24 \mathrm{~h}$ of incubation. The percentage of survival after $24 \mathrm{~h}$ in bile containing condition was evaluated to assess bile salt tolerance.

\section{Hydrophobicity}

Hydrophobicity at cell surface of $L$. brevis
SF121 was determined as following. Briefly, the overnight culture of L. brevis SF121 was washed twice with NSS and centrifuged to harvest the cells. The pellet of bacteria was adjusted to O.D. 0.4 - 0.5 at $600 \mathrm{~nm}(\mathrm{AO})$ with NSS. The bacterial suspension from $\mathrm{A} 0$ was pipet to test tube for $1.2 \mathrm{ml}$ and mixed with $0.2 \mathrm{ml}$ of xylene. After mixing, O.D. $600 \mathrm{~nm}$ measurement of a lower aqueous phase was performed. Calculation of hydrophobicity percentage by using (1-A1/A0) x 100 formula ${ }^{28}$.

\section{Antibiotic susceptibility}

In this study, the MIC of antibiotics, including, ampicillin, chloramphenicol, ciprofloxacin, erythromycin, nalidixic acid, penicillin, tetracycline and vancomycin were determined for antibiotic susceptibility following CLSI (Clinical and laboratory standards institute) guideline. In brief, contained antibiotic MRS broth was transferred to a microplate with a serial two-fold diluted from $512 \mu \mathrm{g} / \mathrm{ml}$ to $1 \mu \mathrm{g} /$ $\mathrm{ml}$. The overnight culture of L. brevis SF121 was diluted with NSS to prepare the suspension equal turbidity to $0.5 \mathrm{McF}$ arland. The prepared L. brevis SF121 suspension was diluted hundred-fold with MRS and transferred to a filled microplate. The MIC was observed and interpreted after overnight incubation at $37^{\circ} \mathrm{C}$.

\section{Antimicrobial activity}

The well diffusion assay was used to assess antimicrobial activity of $L$. brevis SF121. The twenty milliliters of Mueller-Hinton agar plates were prepared and swabbed with the indicator organisms. The indicator organisms in this study, including gram positive bacteria (Bacillus cereus, Staphylococcus aureus, Streptococcus pyogenes, Enterococcus faecium) gram negative bacteria (Escherichia coli, Pseudomonas aeruginosa, Salmonella enterica Typhimurium, Shigella sonnei, Vibrio cholerae) and yeast (Candida albicans). All organisms were cultivated in Mueller-Hinton broth at $37^{\circ} \mathrm{C}$ for overnight before spreading on agar plates. A well on swabbed plate that made from cork borer no. 3 was filled with $100 \mu \mathrm{l}$ of $L$. brevis SF121 overnight culture supernatant, which was prior adjusted the $\mathrm{pH}$ to 7.0 with $1 \mathrm{~N} \mathrm{NaOH}$ and filtered by $0.22 \mu \mathrm{m}$ pore size membrane for sterilization. The plates were measured for the inhibition zone after overnight incubation at $37^{\circ} \mathrm{C}$. 


\section{RESULTS}

\section{Lactobacillus isolation and characterization}

Gram positive rod shaped bacteria with catalase negative and no hemolytic activity was selected from MRS agar. Bile salt hydrolase activity was shown as precipitated halozone around the colony of $L$. brevis SF121 on GDCA-MRS agar plate (Fig. 1) but no activity observed on TDCA-MRS. The isolate also exhibited ability to convert insoluble uric acid in MRS agar plate to soluble form which showed as the clear zone around colony in the Fig. 2.

\section{Lactobacillus identification}

The selected isolate showed $96.6 \%$ identity with Lactobacillus brevis by API $50 \mathrm{CHL}$. The identification was confirmed by $16 \mathrm{~s}$ rRNA sequencing, which indicated coherent result with $99 \%$ identical to $L$. brevis in NCBI database. From isolation and identification, this isolate was designated as Lactobacillus brevis SF121.

Determination of probiotic properties

From general probiotic property characterization, gastric fluid tolerance of the isolate in this study was $67.07 \%$ and bile salt tolerance was $89.62 \%$. The L. brevis SF121 presented $21.44 \%$ hydrophobicity

For antibiotic susceptibility test, the isolate demonstrated sensitivity to only erythromycin and presented resistance to remaining antibiotics in this study (Table 1). Furthermore, all test organisms in the experiment, including gram positive bacteria, gram negative bacteria and yeast, could not be inhibited the growth by $L$. brevis SF121.

\section{DISCUSSION}

From screening and isolation result, Lactobacillus species had been isolated from Pak Sian Dong. Previous study showed that the various genus of lactic acid bacteria can be found in Pak Sian Dong, including Lactobacillus sp. ${ }^{29}$, thus the one report reveals potential of lactobacilli from this source have capability to use as probiotic 27. There was no hemolytic activity presented on blood agar plate which could be confirmed safety of the isolate for further used in animal and human ${ }^{17}$.

Determination of colonizing properties revealed that the isolate can resist simultaneous gastrointestinal environment. Both gastric fluid tolerance and bile salt tolerance are key important properties for survival of probiotic bacteria that appropriate for oral route use $\mathrm{e}^{30}$. The properties confirm that this bacteria can survive and provide beneficial effects to the host at gastrointestinal tract region. For hydrophobicity, the isolate

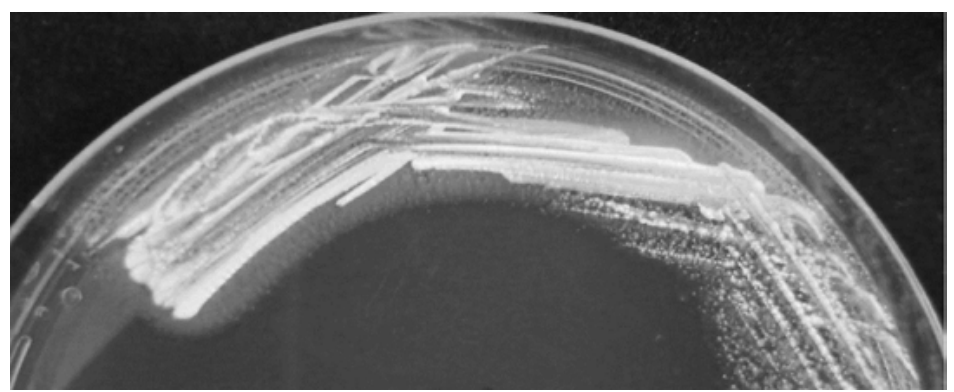

Fig. 1. The L. brevis SF121 on GDCA-MRS medium. The activity of bile salt hydrolase showed with halozone surrounding colonies.

Table 1. Antibiotic susceptibility profiles of L. brevis SF121 isolate

\begin{tabular}{lcccccccc}
\hline & \multicolumn{8}{c}{ Antibiotics $(\mu \mathrm{g} / \mathrm{ml})$} \\
\cline { 2 - 7 } & Ampi & Chlo & Cipr & Eryt & Nali & Peni & Tetr & Vanc \\
\hline $\begin{array}{l}\text { L. brevis } \\
\text { SF121 }\end{array}$ & $\begin{array}{c}32 \\
\text { (Resist) }\end{array}$ & $\begin{array}{c}8 \\
\text { (Resist) }\end{array}$ & $\begin{array}{c}64 \\
\text { (Resist) }\end{array}$ & $\begin{array}{c}0.5 \\
\text { (Sens) }\end{array}$ & $\begin{array}{c}>256 \\
\text { (Resist) }\end{array}$ & $\begin{array}{c}32 \\
\text { (Resist) }\end{array}$ & $\begin{array}{c}16 \\
\text { (Resist) }\end{array}$ & $\begin{array}{c}>256 \\
\text { (Resist) }\end{array}$ \\
\hline
\end{tabular}

The antibiotics in this study consisted of ampicillin (Ampi), chloramphenicol (Chlo), ciprofloxacin (Cipr), erythromycin (Eryt), nalidixic acid (Nali), penicillin (Peni), tetracycline (Tetr) and vancomycin (Vanc). 


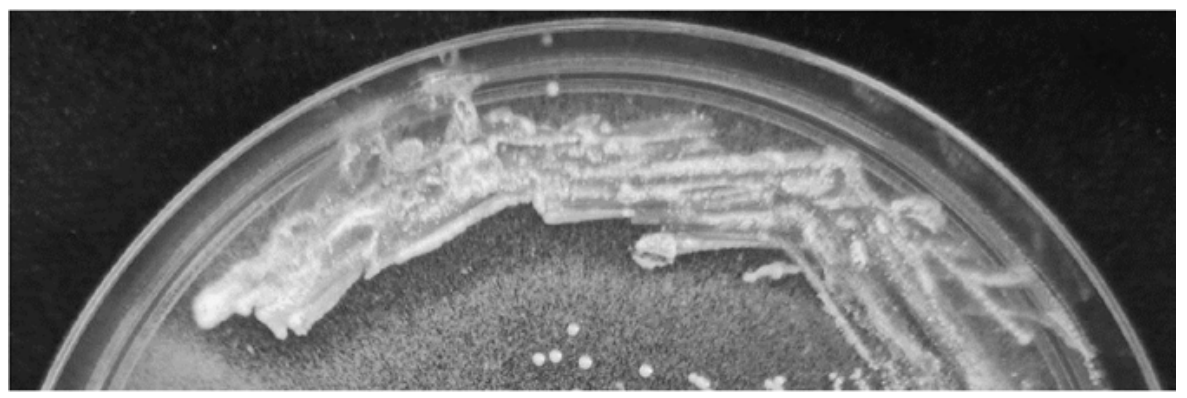

Fig. 2. Uricase activity of L. brevis SF121 presented by clear zone on MRS medium containing uric acid.

showed a little percentage, however the bacteria probably use other mechanisms to attach the epithelium cells such as aggregation property ${ }^{31}$.

The novel isolate has been identified as $L$. brevis, which commonly be found in milk, plants and fermented products. This bacteria can be applied to use in industrial and food technology and normally defined as GRAS (Generally Recognized As Safe) $^{32}$. Some strain of $L$. brevis presented probiotic properties, e.g., antioxidant properties ${ }^{33}$, anti-caries activity ${ }^{34}$, immunomodulating activity ${ }^{35}$ and synergistic with prebiotic for antimicrobial activity ${ }^{36}$.

From the result of bile salt hydrolase, the isolate showed the activity only on MRS agar containing GDCA. This finding conformed to previous study that lactobacilli from Pak Sian Dong have an ability to hydrolyze GDCA but not TDCA $^{27}$. According to bile salt hydrolase activity, this isolate can probably be alternatively used for cholesterol lowering application. Several reports published that lactobacilli, such as L. plantarum $^{37-39}$, L. gasseri ${ }^{40}$, L. johnsonii ${ }^{41,42}$ and L. brevis $^{43}$, could be proved for bile salt hydrolase production. In 2013, L. plantarum with bile salt hydrolase was fed in high-cholesterol diet-induced rat could improve lipid profile in serum and liver of the rat ${ }^{44}$. Another report revealed that lactobacilli with strong expression of bile salt hydrolase have the capability to ameliorate hypercholesterolemia in mouse mode ${ }^{20}$. In accordance with previous evidences, the novel strain, L. brevis SF121, might be able to reduce cholesterol by bile salt hydrolase activity.

Because of uricase enzyme is related to hyperuricemia therapy, this isolate with uricase activity is possibly appropriated to apply in this therapeutic approach. In human, uricase cannot be produced because of the loss of this enzymatic activity by genetic mutation during Miocene epoch ${ }^{45}$. Therefore, the compensation of this enzyme with intestinal microbes might be an important point. The normal route of administration of uricase (Pegloticase) is intravenous but there is a report that oral uricase administration in animal showed elimination of uric acid ${ }^{46,47}$. Moreover, alteration of Lactobacillus genus show relation with hyperuricemia in animal mode ${ }^{48}$ so the adjustment of lactobacilli population probably a helpful for treatment.

\section{CONCLUSION}

L. brevis SF121, which isolated from fermented spider plant or Pak Sian Dong in this study, found ability to present bile salt hydrolase and uricase activity. This isolate is probably able to use for reducing of cholesterol and uric acid in person who is defined as hypercholesterolemia and hyperuricemia. This isolate exhibited resistance to gastrointestinal condition and survived in proper time for using as oral probiotic bacteria. Due to possibility to find the bacteria with bile salt hydrolase and uricase activity in Pak Sian Dong, this kind of fermented food would be established as a health beneficial food and also a good source for probiotic bacteria screening. However, there are several properties of probiotic needs to be conducted in future study for probiotic authentication of the L. brevis SF121 isolate.

\section{ACKNOWLEDGMENTS}

We would like to thank Chulabhorn International College of Medicine for all facilities. 
This research was supported by Thammasat University, Thailand.

\section{CONFLICT OF INTEREST}

The authors declare that there is no conflict of interest.

\section{AUTHORS' CONTRIBUTION}

All authors listed have made a substantial, direct and intellectual contribution to the work, and approved it for publication.

\section{FUNDING}

None.

\section{DATA AVAILABILITY}

All datasets generated or analyzed during this study are included in this manuscript.

\section{ETHICS STATEMENT}

This article does not contain any studies with human or animal experiments by any of the authors.

\section{REFERENCES}

1. Swain MR, Anandharaj M, Ray RC, Rani RP. Fermented fruits and vegetables of Asia: a potential source of probiotics. Biotechnol Res Int. 2014;2014:250424. doi: 10.1155/2014/250424

2. Azam M, Mohsin M, ljaz H, et al. Review - Lactic acid bacteria in traditional fermented Asian foods. Pak J Pharm Sci. 2017;30(5):1803-1814. PMID: 29084705

3. Barla F, Koyanagi T, Tokuda N, et al. The gammaaminobutyric acid-producing ability under low $\mathrm{pH}$ conditions of lactic acid bacteria isolated from traditional fermented foods of Ishikawa Prefecture, Japan, with a strong ability to produce ACE-inhibitory peptides. Biotechnol Rep (Amst). 2016;10:105-110. doi: 10.1016/j.btre.2016.04.002

4. Doan NT, Van Hoorde K, Cnockaert M, et al. Validation of MALDI-TOF MS for rapid classification and identification of lactic acid bacteria, with a focus on isolates from traditional fermented foods in Northern Vietnam. Lett App/ Microbiol. 2012;55(4):265-273. doi: 10.1111/j.1472-765X.2012.03287.x

5. Mokoena MP, Mutanda T, Olaniran AO. Perspectives on the probiotic potential of lactic acid bacteria from African traditional fermented foods and beverages. Food Nutr Res. 2016;60:29630. doi: 10.3402/fnr. v60.29630

6. Ouoba LII, Nyanga-Koumou CAG, Parkouda C, et al. Genotypic diversity of lactic acid bacteria isolated from African traditional alkaline-fermented foods. J Appl Microbiol. 2010;108(6):2019-2029. doi: 10.1111/j.1365-2672.2009.04603.x
7.

Kumar RS, Kanmani P, Yuvaraj N,Paari KA, Pattukumar V, Arul V. Traditional Indian fermented foods: a rich source of lactic acid bacteria. Int J Food Sci Nutr. 2013;64(4):415428. doi: 10.3109/09637486.2012.746288

8. Smitinont T, Tansakul C, Tanasupawat S, et al. Exopolysaccharide-producing lactic acid bacteria strains from traditional Thai fermented foods: isolation, identification and exopolysaccharide characterization. Int J Food Microbiol. 1999;51(23):105-111. doi: 10.1016/S0168-1605(99)00094-X

9. Son $\mathrm{SH}$, Jeon $\mathrm{HL}$, Yang SJ, et al. Probiotic lactic acid bacteria isolated from traditional Korean fermented foods based on beta-glucosidase activity. Food Sci Biotechnol. 2018;27(1):123-129. doi: 10.1007/s10068017-0212-1

10. Yu J, Wang HM, Zha MS, et al. Molecular identification and quantification of lactic acid bacteria in traditional fermented dairy foods of Russia. J Dairy Sci. 2015;98(8):5143-5154. doi: 10.3168/jds.2015-9460

11. Ji K, Jang NY, Kim YT. Isolation of Lactic Acid Bacteria Showing Antioxidative and Probiotic Activities from Kimchi and Infant Feces. J Microbiol Biotechnol. 2015;25(9):1568-1577. doi: 10.4014/jmb.1501.01077

12. Touret $\mathrm{T}$, Oliveira M, Semedo-Lemsaddek T. Putative probiotic lactic acid bacteria isolated from sauerkraut fermentations. PLoS One. 2018;13(9):e0203501. doi: 10.1371/journal.pone.0203501

13. Yu Z, Zhang X, Li S, Li C, Li D, YangZ. Evaluation of probiotic properties of Lactobacillus plantarum strains isolated from Chinese sauerkraut. World J Microbiol Biotechnol. 2013;29(3):489-498. doi: 10.1007/s11274012-1202-3

14. Onyango CM KC, Ontita EG, Narla RD, Kimenju JW. Current status on production and utilization of spider plant (Cleome gynandra L.) an underutilized leafy vegetable in Kenya. Genet Resour Crop Ev. 2013;60(7):2183-2189. doi: 10.1007/s10722-0130036-7

15. Devi SM, Archer AC, Halami PM. Screening, Characterization and In Vitro Evaluation of Probiotic Properties Among Lactic Acid Bacteria Through Comparative Analysis. Probiotics Antimicrob Proteins. 2015;7(3):181-192. doi: 10.1007/s12602-015-9195-5

16. Gotteland M, Cires MJ, Carvallo C, et al. Probiotic screening and safety evaluation of Lactobacillus strains from plants, artisanal goat cheese, human stools, and breast milk. J Med Food. 2014;17(4):487-495. doi: 10.1089/jmf.2013.0030

17. Zhang $F$, Jiang $M$, Wan $C$, et al. Screening probiotic strains for safety: Evaluation of virulence and antimicrobial susceptibility of enterococci from healthy Chinese infants. J Dairy Sci. 2016;99(6):4282-4290. doi: 10.3168/jds.2015-10690

18. Kumar R, Grover S, Batish VK. Bile Salt Hydrolase (Bsh) Activity Screening of Lactobacilli: In Vitro Selection of Indigenous Lactobacillus Strains with Potential Bile Salt Hydrolysing and Cholesterol-Lowering Ability. Probiotics Antimicrob Proteins. 2012;4(3):162-172. doi: 10.1007/s12602-012-9101-3

19. Jones $\mathrm{ML}$, Martoni $\mathrm{CJ}$, Parent $\mathrm{M}$, et al. Cholesterollowering efficacy of a microencapsulated bile salt hydrolase-active Lactobacillus reuteri NCIMB 30242 
yoghurt formulation in hypercholesterolaemic adults. Br J Nutr. 2012;107(10):1505-1513. doi: 10.1017/ S0007114511004703

20. Wang G, Huang W, Xia Y, et al. Cholesterol-lowering potentials of Lactobacillus strain overexpression of bile salt hydrolase on high cholesterol dietinduced hypercholesterolemic mice. Food Funct. 2019;10(3):1684-1695. doi: 10.1039/C8FO02181C

21. Kelley WN, Wyngaarden JB. Drug treatment of gout. Semin Drug Treat. 1971;1(2):119-147.

22. Biggers K, Scheinfeld N. Pegloticase, a polyethylene glycol conjugate of uricase for the potential intravenous treatment of gout. Curr Opin Investig Drugs. 2008;9(4):422-429.

23. Nanda P, Babu PE. Isolation, screening and production studies of uricase producing bacteria from poultry sources. Prep Biochem Biotechnol. 2014;44(8):811821. doi: $10.1080 / 10826068.2013 .867875$

24. Mahler JL. A new bacterial uricase for uric acid determination. Anal Biochem. 1970;38(1):65-84. doi: 10.1016/0003-2697(70)90156-9

25. Shaaban MI, Abdelmegeed E, Ali YM. Cloning, expression, and purification of recombinant uricase enzyme from Pseudomonas aeruginosa Ps43 using Escherichia coli.J Microbiol Biotechnol. 2015;25(6):887892. doi: 10.4014/jmb.1410.10041

26. Iswantini D, Nurhidayat N, Trivadila, et al. Activity and stability of uricase from Lactobacillus plantarum immobilizated on natural zeolite for uric acid biosensor. Pak J Biol Sci. 2014;17(2):277-281. doi: 10.3923/ pjbs.2014.277.281

27. Yasiri A, Vannaxay, E, Kiatmontri J,d Seubsasana S. Isolation and determination of bile salt hydrolaseproducing lactic acid bacteria from fermented spider plant. J Pure Appl Microbiol. 2018;12(3):1055-1060. doi: 10.22207/JPAM.12.3.03

28. Mota RM, Moreira JL, Souza MR, et al. Genetic transformation of novel isolates of chicken Lactobacillus bearing probiotic features for expression of heterologous proteins: a tool to develop live oral vaccines. BMC Biotechnol. 2006;6:2. doi: 10.1186/1472-6750-6-2

29. Tanasupawat S, Komagata K. Lactic acid bacteria in fermented foods in Thailand. World J Microbiol Biotechnol. 1995;11(3):253-256. doi: 10.1007/ BF00367094

30. Zhang B, Wang Y, Tan Z, et al. Screening of probiotic activities of lactobacilli strains isolated from traditional Tibetan Qula, a raw yak milk cheese. Asian-Australas J Anim Sci. 2016;29(10):1490-1499. doi: 10.5713/ ajas.15.0849

31. Tuo $\mathrm{Y}, \mathrm{Yu} H, \mathrm{Ai}$ L, et al. Aggregation and adhesion properties of 22 Lactobacillus strains. J Dairy Sci. 2013;96(7):4252-7. doi: 10.3168/jds.2013-6547

32. Ronka E, Malinen E, Saarela M, et al. Probiotic and milk technological properties of Lactobacillus brevis. Int J Food Microbiol. 2003;83(1):63-74. doi: 10.1016/ S0168-1605(02)00315-X

33. Shakibaie M, Mohammadi-Khorsand T, Adeli-Sardou M, et al. Probiotic and antioxidant properties of seleniumenriched Lactobacillus brevis LSe isolated from an Iranian traditional dairy product. J Trace Elem Med
Biol. 2017;40:1-9. doi: 10.1016/j.jtemb.2016.11.013

34. Fang $F, \mathrm{Xu} \mathrm{J}, \mathrm{Li} \mathrm{Q}$, et al. Characterization of a Lactobacillus brevis strain with potential oral probiotic properties. BMC Microbiol. 2018;18(1):221. doi: 10.1186/s12866-018-1369-3

35. Song MW, Jang HJ, Kim KT, et al. Probiotic and Antioxidant Properties of Novel Lactobacillus brevis KCCM 12203P Isolated from Kimchi and Evaluation of Immune-Stimulating Activities of Its Heat-Killed Cells in RAW 264.7 Cells. J Microbiol Biotechnol. 2019;29(12):1894-903. doi: 10.4014/jmb.1907.07081

36. Kariyawasam K, Yang SJ, Lee NK, et al. Probiotic Properties of Lactobacillus brevis KU200019 and Synergistic Activity with Fructooligosaccharides in Antagonistic Activity against Foodborne Pathogens. Food Sci Anim Resour. 2020;40(2):297-310. doi: 10.5851/kosfa.2020.e15

37. Gu XC, Luo XG, Wang CX, et al. Cloning and analysis of bile salt hydrolase genes from Lactobacillus plantarum CGMCC No. 8198. Biotechnol Lett. 2014;36(5):975-983. doi: 10.1007/s10529-013-1434-9

38. Lambert JM, Bongers RS, de Vos WM, et al. Functional analysis of four bile salt hydrolase and penicillin acylase family members in Lactobacillus plantarum WCFS1. Appl Environ Microbiol. 2008;74(15):4719-4726. doi: 10.1128/AEM.00137-08

39. Kumar R, Grover S, Batish VK. Hypocholesterolaemic effect of dietary inclusion of two putative probiotic bile salt hydrolase-producing Lactobacillus plantarum strains in Sprague-Dawley rats. Br J Nutr. 2011;105(4):561-573. doi: 10.1017/ S0007114510003740

40. Rani RP, Anandharaj M, Ravindran AD. Characterization of Bile Salt Hydrolase from Lactobacillus gasseri FR4 and Demonstration of Its Substrate Specificity and Inhibitory Mechanism Using Molecular Docking Analysis. Front Microbiol. 2017;8:1004. doi: 10.3389/ fmicb.2017.01004

41. Travers MA, Sow C, Zirah S, et al. Deconjugated bile salts produced by extracellular bile-salt hydrolaselike activities from the probiotic Lactobacillus johnsonii La1 inhibit Giardia duodenalis in vitro growth. Front Microbiol. 2016;7:1453. doi: 10.3389/ fmicb.2016.01453

42. Elkins CA, Savage DC. Identification of genes encoding conjugated bile salt hydrolase and transport in Lactobacillus johnsonii 100-100. J Bacteriol. 1998;180(17):4344-4349. doi: 10.1128/ JB.180.17.4344-4349.1998

43. Reyes-Nava L, Garduno-Siciliano L, Estrada-de los Santos P, et al. Use of bile acids as a selection strategy for lactobacillus strains with probiotic potential. J Food Nutr Disor. 2016;5(1).

44. Huang $Y$, Wang $X$, Wang J, et al. Lactobacillus plantarum strains as potential probiotic cultures with cholesterollowering activity. J Dairy Sci. 2013;96(5):2746-2753. doi: 10.3168/jds.2012-6123

45. Alvarez-Lario B, Macarron-Vicente J. Uric acid and evolution. Rheumatology (Oxford). 2010;49(11):20102015. doi: 10.1093/rheumatology/keq204

46. Chen RJ, Chen MH, Chen YL, et al. Evaluating the urate-lowering effects of different microbial fermented 
Yasiri \& Seubsasana | J Pure Appl Microbiol | 14(3):1715-1722 | September 2020 | https://doi.org/10.22207/JPAM.14.3.10

extracts in hyperuricemic models accompanied with a safety study. J Food Drug Anal. 2017;25(3):597-606. doi: 10.1016/j.jfda.2016.07.003

47. Szczurek P, Mosiichuk N, Wolinski J, et al. Oral uricase eliminates blood uric acid in the hyperuricemic pig model. PLoS One. 2017;12(6):e0179195. doi: 10.1371/ journal.pone.0179195

48. Yu Y, Liu Q, Li H, Wen C, He Z. Alterations of the Gut Microbiome Associated With the Treatment of Hyperuricaemia in Male Rats. Front Microbiol. 2018;9:2233. doi: 10.3389/fmicb.2018.02233 